\title{
Multidimensional segmentation at work: Driving an operational model that integrates customer segmentation with customer management
}

Received (in revised form): 14th November, 2004

\section{Melody Badgett}

is Managing Consultant at the IBM Institute for Business Value.

\section{Merlin Stone}

is Business Research Leader at IBM Business Consulting Services, IBM Professor of Relationship Marketing at Bristol Business School, and Director at The Database Group Ltd, Digital Data Analysis Ltd, The Halo Works Ltd, NowellStone Ltd and QCi Ltd.

Abstract This paper describes a study carried out by the IBM Institute for Business Value focusing on how companies use segmentation. It shows that although segmentation is widely used, there are significant opportunities for companies to improve their approach to segmentation, in particular by adding the time dimension and by expanding the use of segmentation beyond traditional marketing uses.

This paper refers to and includes material reprinted by permission from the 'IBM Institute for Business value survey and analysis' copyright 2003 by International Business Machines Corporation.

\section{INTRODUCTION}

The main aim of market segmentation is to understand customers better, and to use that understanding to improve profitability, or whatever other measure of stakeholder value is appropriate to the type of organisation, eg for charities and government organisations, measures of value to address donors and recipients more cost-effectively, or to ensure adoption of services. Effective segmentation helps companies increase revenue by improving targeting, by making it easier to meet customers' needs, which typically leads to some combination of increased customer numbers, particularly customers of the 'right' value, higher revenue per customer and improved customer retention. It can also help in aligning cost-to-serve to customer value, perhaps reducing overall marketing, sales and service costs.

So much for the theory. The purpose of the study described in this paper was to see how far the theory of segmentation is applied in practice, in all areas from corporate strategy and product policy, through channel choice and management, to how individual customers are managed. The good news is that many companies have made enormous progress in deploying and pursuing multidimensional, dynamic segmentation: the benefits achieved range from rapid, stable sales growth to 30 to 50 per cent increases in customer retention of customer assets. 
In best practice companies, knowing customers has become a way of life with segmentation used across functions and at different levels for many different purposes. There are, however, still weaknesses in areas such as blending attitudinal research with customer databases, with identifying how customers change over time. Further, deploying segmentation is not just a matter of analysis. Only the most advanced companies successfully combine the latest technological and analytical advances to deploy segmentation in interactions with individual customers.

\section{SURVEY METHODOLOGY}

In 2003, a market research company specialising in online surveys sent a survey to 2,000 executives in marketing and sales in companies with over US $\$ 100 \mathrm{~m}$ in annual revenue. The survey consisted of 21 questions - multiple choice, rating scales and open-ended questions. One hundred and twenty-two responses were received, a 6.1 per cent response rate. In addition, in-depth interviews were carried out with 15 executives. Forty-five per cent of the interviewees were executives of global companies, the majority based in the USA.

The interviews covered the following companies:

- top financial services company: director, e-commerce and retail segments;

- top financial services company: director, customer strategies group;

— top investment management firm: executive vice president (EVP), customer strategy;

- top ten US insurance company: vice president, customer and marketing intelligence;

— top international hospitality company: vice president, customer marketing;

- top international hospitality company: vice president, brand research;

— leading travel company: former executive;

- top office supply company: vice president, small business marketing;

- leading consumer packaged goods (CPG) company: director, category growth;

- leading US retailer: manager, marketing analytics;

- leading US diversified retailer: director, market research and director, CRM team;

- premier international athletic footwear company: vice president technology and operations;

— international leader in health products and services: vice president marketing analysis;

- specialised online nutrition services company: vice president weight loss services;

- leading international customer management software company: senior vice president (SVP), worldwide marketing.

Figures 1 and 2 show the split of respondents by industry and revenue.

\section{TYPES OF SEGMENTATION USED AND PROBLEMS FACED}

As Figure 3 shows, the range of segmentation used is quite limited, with most companies using fairly straightforward methods. The positive news, however, is that companies are combining approaches to achieve more discrimination and better insight. As Figure 4 shows, however, the main problem faced by companies relates to two quite fundamental issues - when to resegment, and whether segmentation pays. The two are, of course, closely related. As in many industries, the key to getting value from segmentation is 


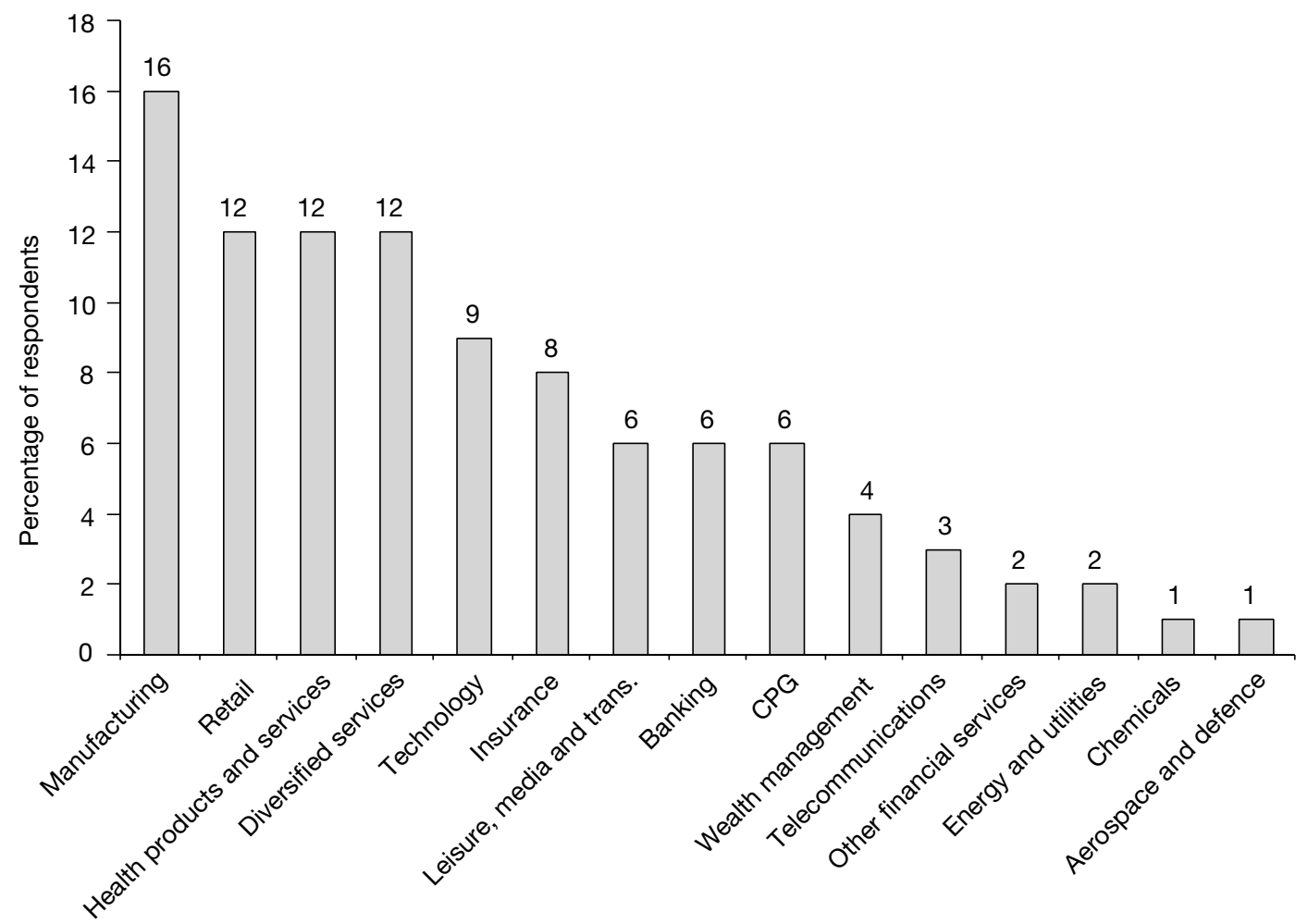

Figure 1 Distribution of respondents by industry (IBM quantitative online survey, 122 responses) Courtesy of International Business Machines Corporation

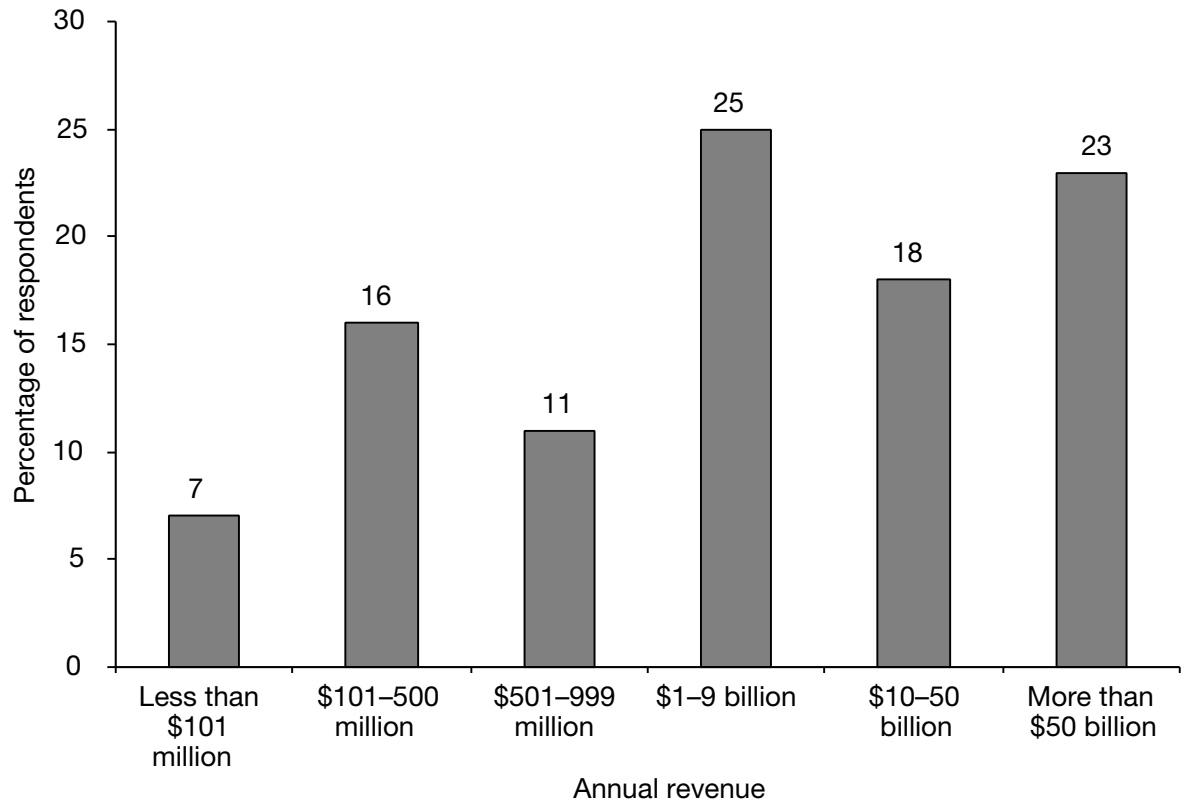

Figure 2 Distribution of respondents by revenue (IBM quantitative online survey, 122 responses) Courtesy of International Business Machines Corporation 
Segmentation types:

Which segmentation methods does your company use?

(Select all that apply)

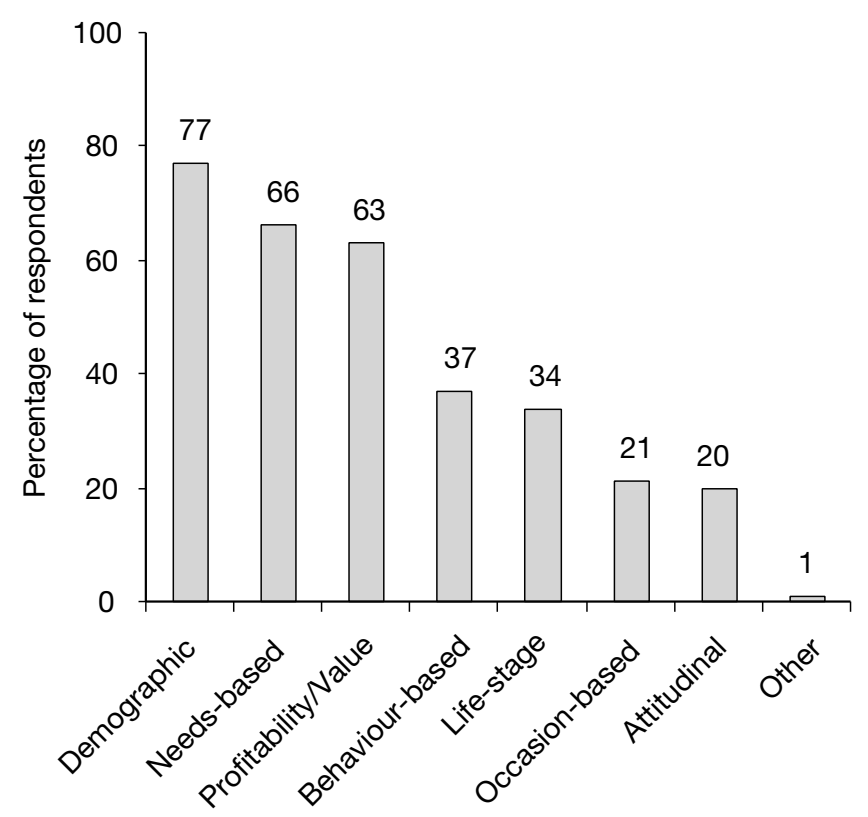

Multi-dimensional segmentation approach:

Do you use multiple segmentation methods (multi-dimensional segmentation) in each segmentation effort (eg combining needs-based segmentation with behaviour-based segmentation)?

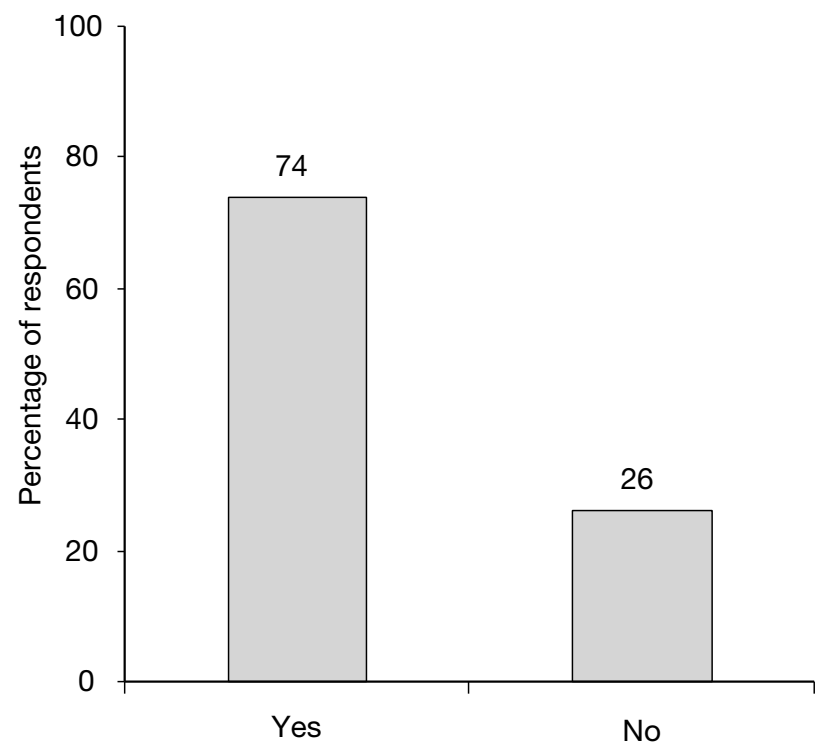

Use of multidimensional segmentation

Figure 3 Types of segmentation used (IBM quantitative online survey, 122 responses) Courtesy of International Business Machines Corporation 


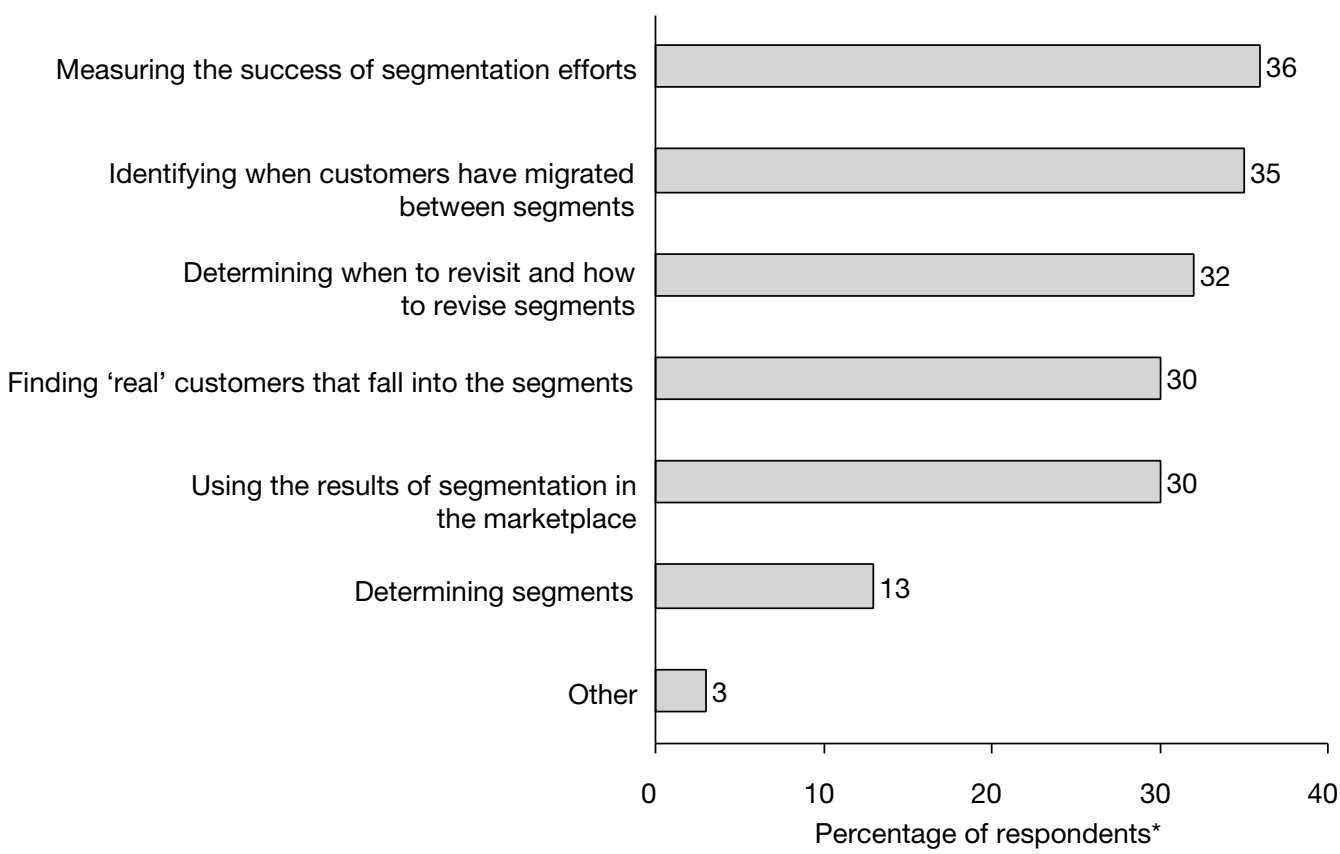

Figure 4 Segmentation challenges: Overall, what are the biggest segmentation challenges your company faces? (choose top 2) (IBM quantitative online survey, 122 responses) Courtesy of International Business Machines Corporation

determining how frequently to track movement of customers among segments and when to resegment.

\section{THREE BUILDING BLOCKS OF EFFECTIVE SEGMENTATION}

In the current study, the authors identified three strong focus areas for effective deployment of segmentation segment characteristics, time characteristics and profitability or value.

\section{Segment characteristics}

- who are customers;

- what do they look like;

- what do they need;

- how do they act;

- what do they buy;

- why do they want it?

Time characteristics

— customer life cycle;
— recency and frequency of purchasing;

- customer life stage;

- channel choice.

Profitability or value

— share of wallet;

— amount spent per purchase;

- cost to serve.

Of course, not all these variables are needed in a particular segmentation, nor does each variable carry the same importance weighting. The most advanced companies use methods ranging from statistical modelling to trial and error to find out which variables are most useful for the particular purpose for which segmentation is being used. Segmentation uses may be strategic or tactical, companywide or initiative-based, one-on-one customer management or managing groups of customers. The purpose may range from corporate strategy, through product or channel 
Strategic

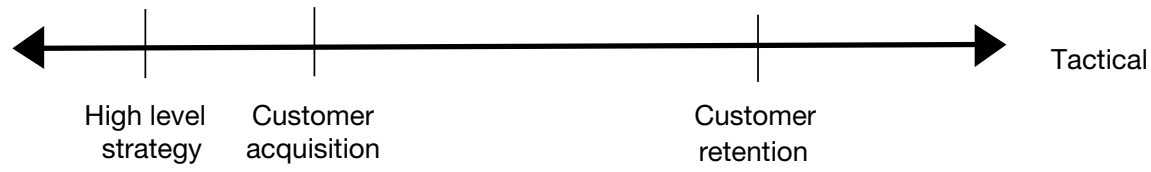

Core
business

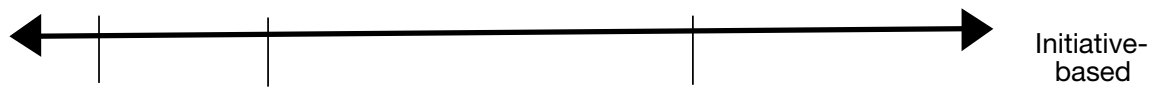

$\begin{array}{ccc}\begin{array}{c}\text { Planning and } \\ \text { forecasting }\end{array} & \begin{array}{c}\text { Line of } \\ \text { business }\end{array} & \text { New product and } \\ \text { service development }\end{array}$

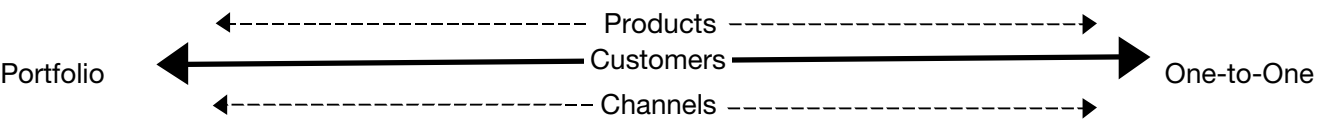

Figure 5 Purposes and levels of segmentation

Courtesy of International Business Machines Corporation

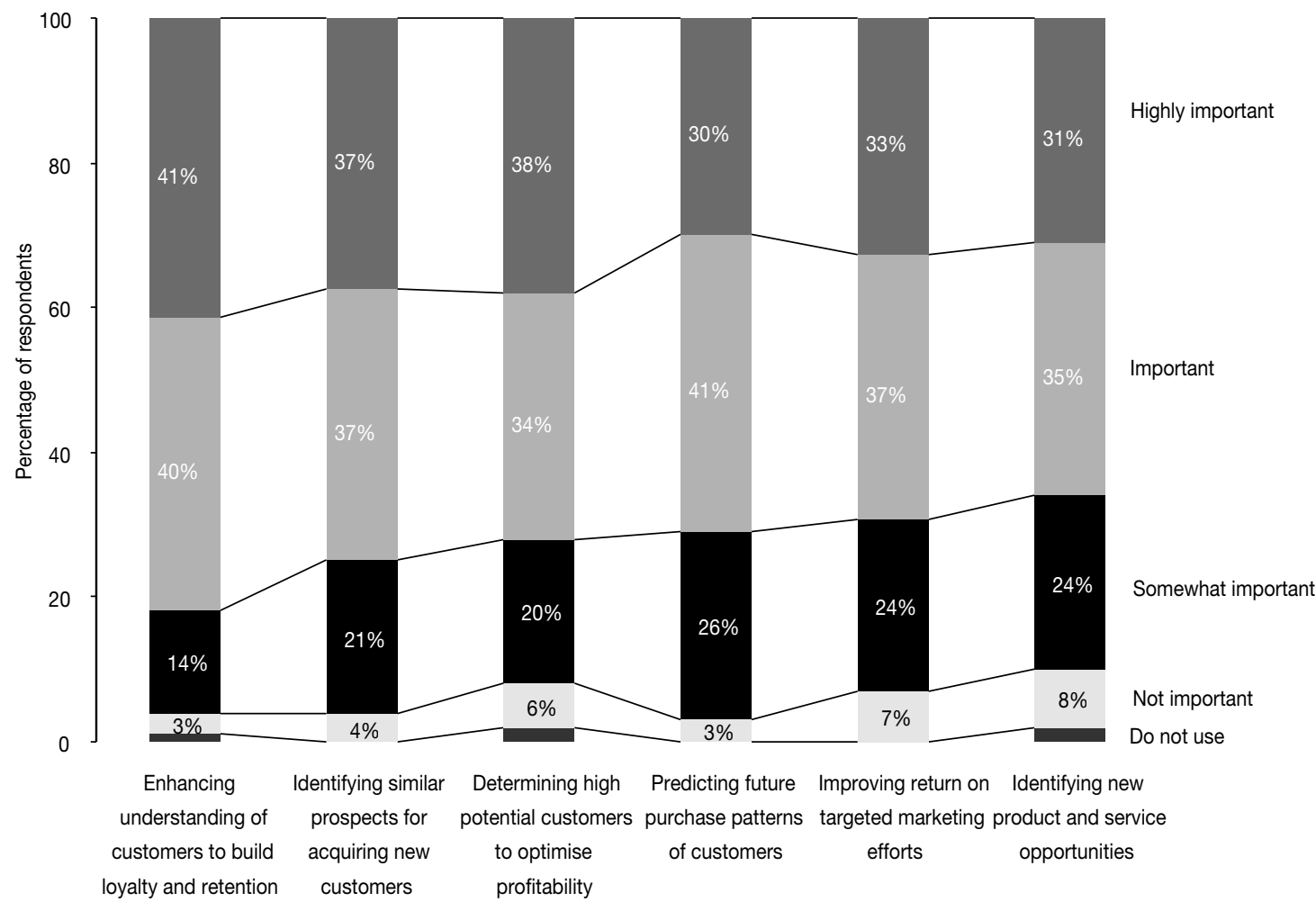

Figure 6 Use of segmentation in marketing. (How important is customer segmentation in the successful execution of the following activities? IBM quantitative online survey, 122 responses)

Courtesy of International Business Machines Corporation

policy, to targeting and managing individual customers. This paper shows how successful companies not only use segmentation to reach profitable customers, but also how they make segmentation a way of life in their companies, diffusing it into all areas of the organisation to improve top and 


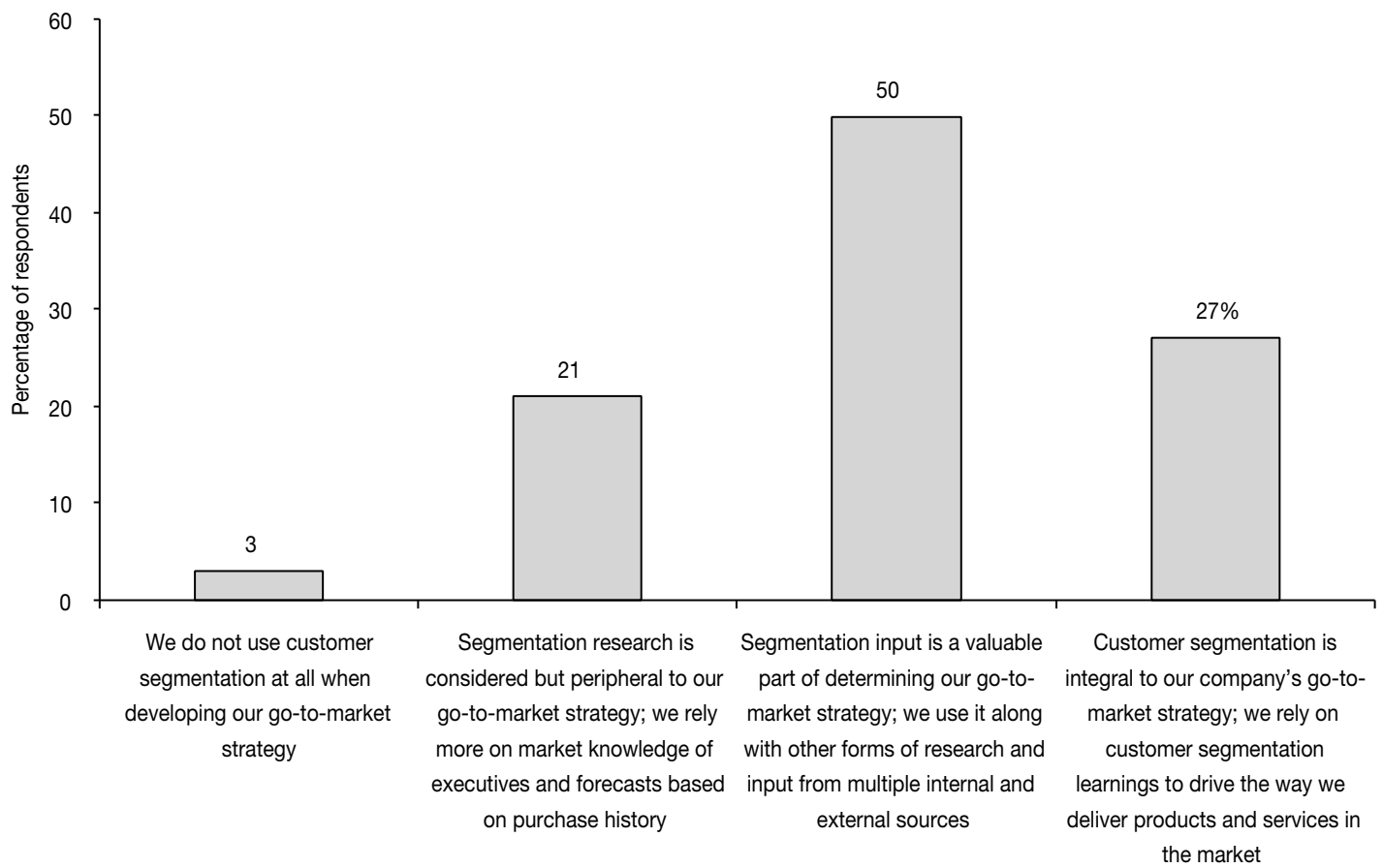

Figure 7 Use of segmentation in go-to-market strategy development: How do findings from your customer segmentation research influence your company's go-to-market strategy? (Select the most applicable statement) (IBM quantitative online survey, 122 responses)

Courtesy of International Business Machines Corporation

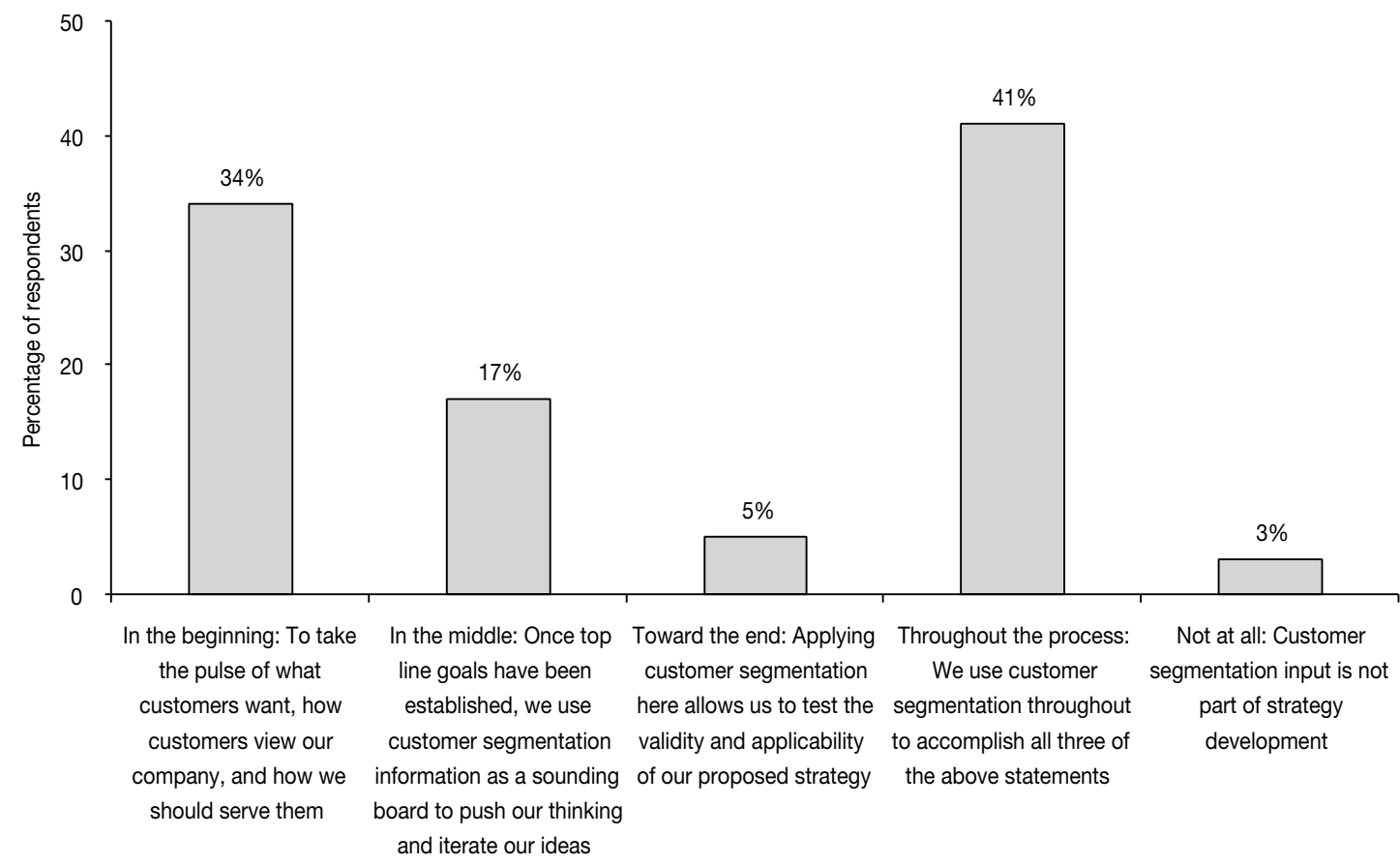

Figure 8 Using segmentation data in strategy development: When in the strategy development process is customer segmentation used? (Select the most applicable answer) (IBM quantitative online survey, 122 responses)

Courtesy of International Business Machines Corporation 


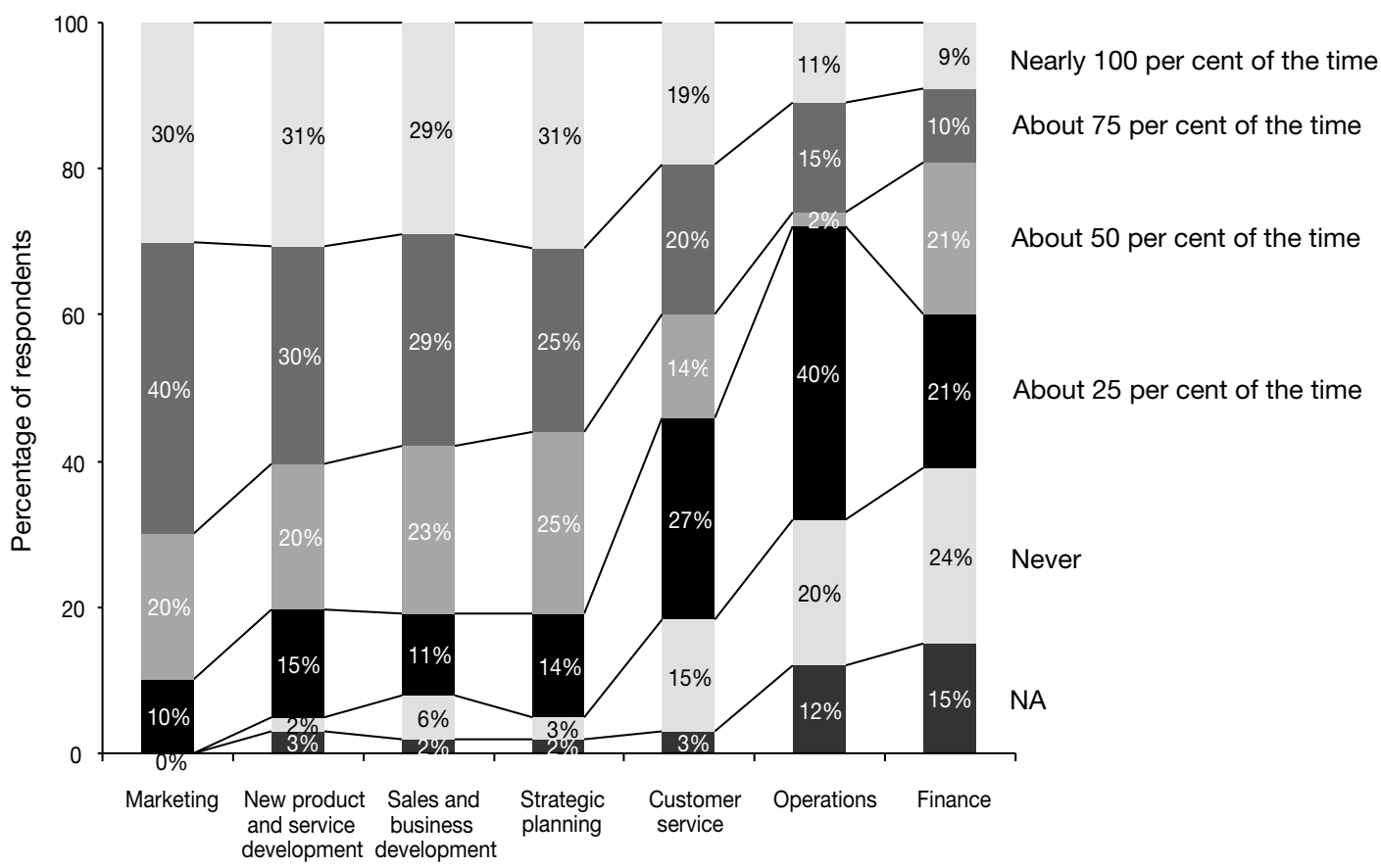

Figure 9 Use of segmentation by functional areas: how regularly does each of the functional areas in your company use customer segmentation to support its initiatives and endeavours? (IBM quantitative online survey, 122 responses)

Courtesy of International Business Machines Corporation

bottom-line business performance. The opportunities that are open to companies for further deployment of segmentation are shown.

\section{WHAT EFFECTIVE SEGMENTATION LOOKS LIKE}

Customer segmentation is no longer a simple, or static, marketing technique. It is central to how successful companies run their business. Of the companies surveyed, 77 per cent cited segmentation as a valuable part of their go-to-market strategy and 97 per cent relied on segmentation in strategy development. The companies interviewed use customer segmentation for many purposes and conduct segmentation studies at many levels, as shown in Figures 5 and 6 . There is some variety in the use of segmentation in strategy, as Figures 7 and 8 show. As Figure 9 shows, however, use of segmentation outside marketing is much weaker.

Depending on the goal, segmentation can be simple or complex, one-dimensional or multifaceted. One leading consumer packaged goods company uses segmentation for strategic, high-level decisions that have an impact upon the core business and affect the entire portfolio of products, customers and channels. The company also uses segmentation data to direct more tactical, discrete initiatives such as targeting a single customer segment or channel. At a high level, this company uses segmentation to aggregate and allocate its advertising media buying. Segmentation tells the company which advertising campaigns and brand positioning will appeal to which segments. From this, the company allocates portions of its advertising spend across multiple products and lines of business while targeting other portions to specific channels and 
customers, while taking advantage of economies of scale of the aggregate spend. At a tactical level, the company uses segmentation to help design new products to meet the changing needs of specific customer segments.

To get full value from segmentation and apply it correctly, companies must use dynamic segmentation - in other words, tracking the movement of customers among segments. Customers are on the move, learning and changing. Companies have to know not only what customers look like today, next week and next month, but also how they will act. Through segmentation, companies can manage their portfolio of customers. Best practice companies use segmentation to tell them:

- with highly profitable customers: what they can do to keep these customers and keep them spending and how they can attract more like them;

- with profitable customers: how they get more of these customers to behave (spend) like their highly profitable ones;

- with unprofitable customers: how they phase out these customers and, in the meantime, serve them economically, and perhaps convert some to profitability.

Almost three-quarters of the companies surveyed rely on a multidimensional view of the customer. Multidimensional means having a complete picture of the customer: who they are, what they look like, what they need, how they act, what they buy, when they buy and why they buy. Why customers buy may be ignored because the information is hard to obtain or because management views attitudinal data as 'soft'. It is the 'why' that drives many of the choices consumers make; why explains motivations behind purchases, and it accounts for nearly half of the purchasing decisions customers make. ${ }^{1}$

Many companies are weak in the use of time-based segmentation, which leads to them being able to reach their customers at the right time. Of the survey respondents, only 37 per cent use behavioural, only 34 per cent use life stage, and only 21 per cent use occasion-based segmentation characteristics. Time variables are critical because they highlight how customers and their buying phases change over time. It is not enough for a company to ask: 'which customers should be targeted?' and 'how much will a customer buy?'. To be effective, segmentation must answer: 'which customers should be targeted when?' and 'how much will a customer buy, and how often will a customer buy, with what recency will a customer buy, where is each customer in his/her buying phase, and what is predicted purchase propensity?'. Companies should track customers as they grow and change to identify points of choice - times in a customer's life when they change how they buy.

As one executive from a leading diversified retailer told us, 'Identifying segments and knowing a little about them is not enough; you have to know a lot about them'. Effective segmentation must be both qualitative and quantitative. To make accurate, segmentation-driven decisions, companies must measure profitability at many levels, including individual, sub-segment, segment, and the total customer portfolio level. Companies must figure out measures of value, eg profitability variables that work best for them. In this research, measures varied by industry and by company, from recency, frequency, monetary (RFM), to customer value indices, to revenue per customer versus cost to serve.

Companies that identify customers' changing patterns (defined as the 


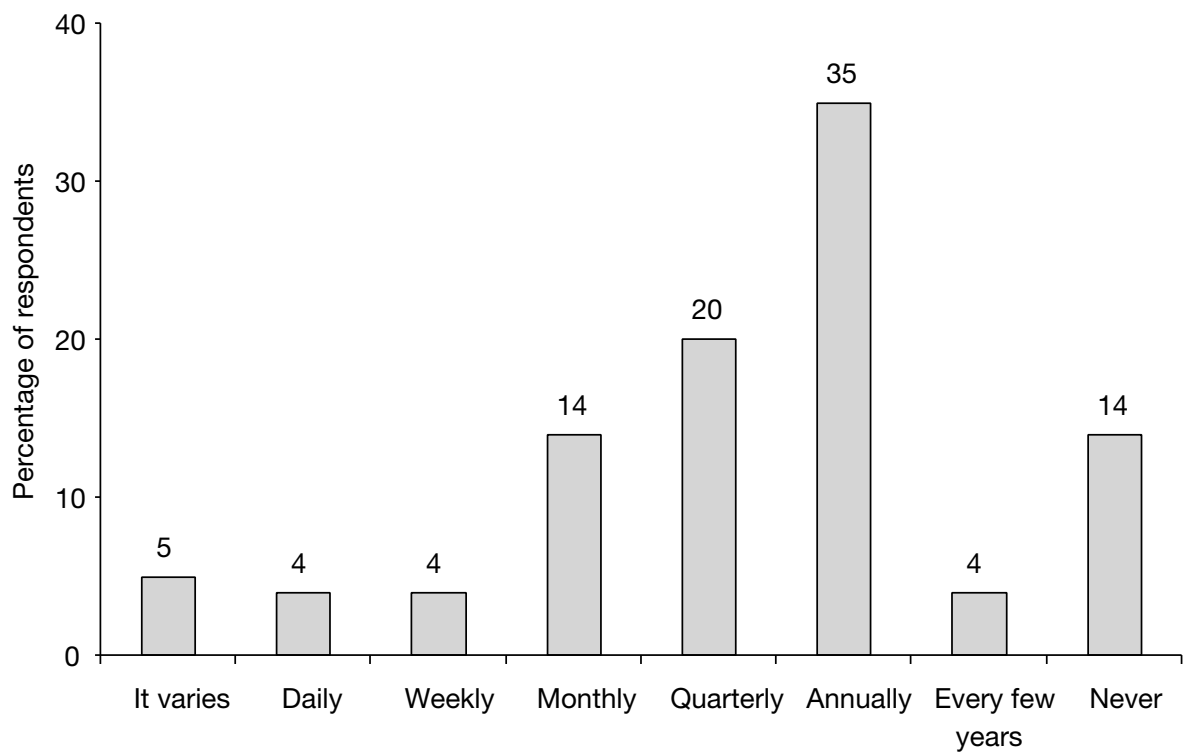

Figure 10 Frequency of tracking and re-evaluating customer profiles to identify if customers have migrated between segments (IBM Quantitative online survey, 122 responses); 'It varies' and 'Every few years' were added to graph responses from respondents who selected 'other, please explain' Courtesy of International Business Machines Corporation

interaction of the three: segment characteristics, time and profitability) win over their competitors by acting first to reach customers at their points of choice (the times when their purchase behaviours change). Analysis of changing patterns involves predictive modelling and research to explain why patterns are changing. Examples of questions that might be asked in this analysis include:

- why some customers buy differently at different times;

- why and when their overall buying patterns change;

- whether changes in buying patterns suggest potential defection;

- what segment characteristics indicate higher or lower future purchases;

- why particular customers suddenly stop buying - overall or particular categories of product.

Policy questions which might be asked as a result of buying pattern analysis include:
- what can be done to encourage lower value customers to become higher value customers;

- what can be done to win back customers that look like defecting;

- what communications or promotions should be sent to customers to prompt a purchase? To prevent defection? When should they be sent?

Identifying and acting on customers' changing patterns is critical to beating competitors in the marketplace. One leading retailer uses analysis of changing patterns to focus its marketing and retention efforts. Clusters of customers are plotted on an opportunity map with each of the three building blocks segment characteristics, time and value - representing one axis of the three-dimensional map.

Competitors often have similar target segments, so understanding and acting first on changing patterns can be the differentiator. In the USA, newlyweds spend a total of US\$70bn in their first 
Table 1 Resegmentation approaches

\begin{tabular}{|c|c|c|c|}
\hline & $\begin{array}{l}\text { Nearly real-time } \\
\text { (daily - monthly) }\end{array}$ & $\begin{array}{l}\text { Regularly and often } \\
\text { (monthly - quarterly) }\end{array}$ & $\begin{array}{l}\text { Less often } \\
\text { (quarterly - annually) }\end{array}$ \\
\hline $\begin{array}{l}\text { Industry/ } \\
\text { interviewed company }\end{array}$ & $\begin{array}{l}\text { - Financial services } \\
\text { - Top Five US Asset } \\
\text { Manager }\end{array}$ & $\begin{array}{l}\text { - Distribution/Retailer } \\
\text { - International Leader in } \\
\text { Pharmacy Products } \\
\text { and Services }\end{array}$ & $\begin{array}{l}\text { - Distribution/CPG } \\
\text { - Leading CPG company }\end{array}$ \\
\hline Purpose of segmentation & $\begin{array}{l}\text { - Increasing customer } \\
\text { share of wallet } \\
\text { - Migrating customers to } \\
\text { higher value }\end{array}$ & $\begin{array}{l}\text { - Identifying attractive } \\
\text { new offerings } \\
\text { - Customer retention } \\
\text { - Migrating customers to } \\
\text { higher value }\end{array}$ & $\begin{array}{l}\text { Determining optimal } \\
\text { positioning } \\
\text { - Identifying new offer- } \\
\text { ings for different seg- } \\
\text { ments } \\
\text { - Increasing share of } \\
\text { wallet within growth } \\
\text { segments }\end{array}$ \\
\hline $\begin{array}{l}\text { Nature of customer } \\
\text { interaction }\end{array}$ & $\begin{array}{l}\text { Through the necessary, } \\
\text { regular and frequent } \\
\text { interaction customers } \\
\text { have across multiple } \\
\text { touch points (branch, } \\
\text { online, ATM) }\end{array}$ & $\begin{array}{l}\text { Through in-store and } \\
\text { online shopping for } \\
\text { products that are both } \\
\text { necessary and nice-to- } \\
\text { haves }\end{array}$ & $\begin{array}{l}\text { - Through focus groups } \\
\text { and customer surveys }\end{array}$ \\
\hline Type of data collected & $\begin{array}{l}\text { - Individual customer } \\
\text { data collected at each } \\
\text { customer interaction } \\
\text { - Demographic data } \\
\text { purchased from a third } \\
\text { party }\end{array}$ & $\begin{array}{l}\text { - Individual customer } \\
\text { data collected with } \\
\text { loyalty cards } \\
\text { - Data about customers } \\
\text { as a whole collected } \\
\text { from sales data } \\
\text { - Demographic data } \\
\text { purchased from a third } \\
\text { party }\end{array}$ & $\begin{array}{l}\text { - Customer data collect- } \\
\text { ed in focus groups and } \\
\text { customer surveys } \\
\text { - Data about customers } \\
\text { collected from sales } \\
\text { data } \\
\text { - Demographic data pur- } \\
\text { chased from a third } \\
\text { party }\end{array}$ \\
\hline
\end{tabular}

Courtesy of International Business Machines Corporation

year of marriage, more in one year than an average household spends in ten years. ${ }^{2}$ AOL Time Warner capitalises on this by creating Newlywed Kits. AOL gets to newlyweds before competitors by distributing millions of kits through registry clerks' offices nationwide. Household brands such as Procter \& Gamble, Clorox and Colgate-Palmolive vie for space in the kits.

Despite the potential value of tracking customers' changing patterns, few companies do this well. This means missed opportunities. Not paying attention to changing patterns could result in a company wasting months and dollars targeting a customer who is no longer (or never was) profitable. Figure
10 shows how rarely some companies resegment. Table 1 gives some examples of resegmenting approaches.

To be viable and timely, companies must move away from 'annual' and 'never' tracking of customers. Customers will not wait that long. Royal Bank of Canada (RBC) tracks customers monthly to understand current and future profitability and risk, likelihood for defection, channel preference, propensity to purchase additional products and life stage. The company tracks customer changes and uses predictive analytics and business interpretation to determine what the patterns indicate. For example, a decrease in the number or amount of deposits may indicate a customer is about to defect, or purchase of a mortgage may 
indicate a customer has a need for a home equity line. Customer tracking and customer understanding enable RBC to achieve a 30 per cent response rate on marketing efforts versus the 3 per cent average of the banking industry. ${ }^{3}$

The optimal frequency for tracking customer-segment relationships varies by industry, purpose of segmentation and nature of customer interaction. Financial services companies, for example, have regular and frequent interactions with customers across multiple touchpoints. Thus, offering new products and services at just the right time requires frequent tracking of customer movement, often daily or monthly. Consumer packaged goods companies, on the other hand, interact with customers less often because they transact directly less frequently. Data are collected from these transactions and also through focus groups, customer surveys and sometimes through access to retail loyalty scheme data. For these companies, it may make sense to monitor customer movement every three to 12 months. To avoid missing valuable opportunities, most companies should increase how often they check customer movement. A nutrition company interviewed is succeeding by tracking customers over time the easy way, by having the customers do it themselves. Customers update their records online every 12 weeks. Having detailed, up-to-date records about each customer enables this company to push highly targeted and personalised messages and offers to its clients on a regular basis. This company has a 50 per cent renewal rate for their main service.

\section{USING SEGMENTATION TO REACH PROFITABLE CUSTOMERS}

As noted above, companies pursue segmentation to appeal to old customers in new ways to attract potential customers in innovative ways, and to migrate high potential customers to greater value (see Figure 11).

Applying effective, multidimensional segmentation equips companies to improve traditional uses of segmentation for optimum benefit. In summary, these include the following.

\section{Competitive advantage}

Segmentation is used to identify new sources of competitive advantage by capitalising on changing patterns of loyal customers; a close eye should be kept on customers, then, cater for their changing needs before competitors do. Only 20-35 per cent of companies surveyed do this. Attention should be paid to time-based elements to know how and when customers change and to cater to their changing needs.

\section{Why buy?}

Companies need to understand motivations behind why customers buy. The attitudinal view should be incorporated to understand why customers buy (motivations); this should be linked to other segment characteristics to make viable. Only 20 per cent of companies surveyed do this.

\section{Quantify segmentation}

Clear links to customer profitability should be established and performance tracked. The customer profitabilitysegmentation link should be strtengthened and segmentation used to optimise profitability of the total customer portfolio.

The following cases show how leading companies have improved on each of six traditional marketing activities by making effective use of segmentation, taking 


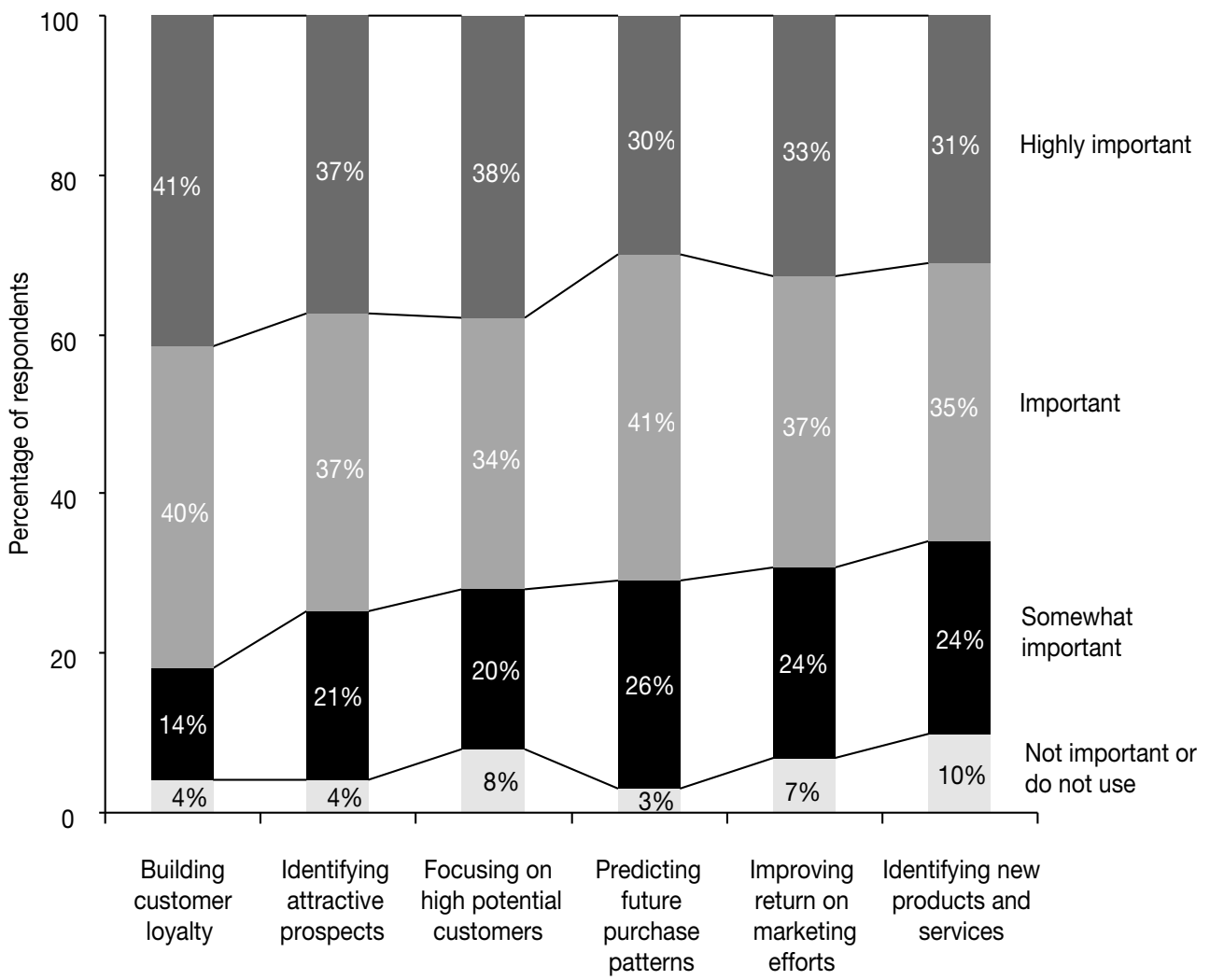

Figure 11 Importance of customer segmentation in reaching profitable customers (IBM quantitative online survey, 122 responses)

Courtesy of International Business Machines Corporation

analysis and resulting actions to the next level. In each case, the company has capitalised on some of the key opportunities for improvement noted above.

\section{Building customer loyalty}

Hallmark is a good example of a company that uses its knowledge of aggregate patterns of customer behaviour to customise marketing offerings and build loyalty. Introduced in 1994, the Hallmark Gold Crown Card loyalty programme was the first consumer reward programme in the greeting card industry. By 2001, Hallmark had 24 million customers in its CRM database, with 13 million of these customers using the Gold Crown Card. The loyalty card allows Hallmark to capture detailed customer data about purchase patterns and purchase history. Aggregating the loyalty card data with point-of-sale customer data and analysing the data enables the company to segment customers according to how they buy. Hallmark's business development manager explains: 'We need to understand as a corporation how, over time, we [can] maximise value and move [customers] up the ladder of loyalty from "prospect" to "buyer" to "hooked". The communication behaviour from us should change as [the customers] move up'. Card members accumulate points that can be used at Hallmark stores and at Hallmark.com. Customers are sent offers 
based on the number of points they have and special promotional offers based on their past purchase history. Promotions and offers are focused on building loyalty through demonstrating understanding of the customer, examples of this include:

- developing marketing campaigns and promotions targeted at different segments of customers, eg collectors of specific product lines are sent promotions about products they collect;

- releasing new product announcements to specific segments of card holders about products in which they may be interested (eg announcements about new seasonal ornaments are sent to avid collectors).

\section{Identifying attractive prospects}

A leading investment management company successfully maps customer segmentation results against external prospect data to identify attractive potential customers. This company segments customers into three primary segments based on current and future value: high value, core, and mass market. Sub-segments, based on potential to become highly profitable, are broken out within each of the three primary segments: high potential (highly profitable, most valuable); cultivate (reasonably profitable, much possible upside); manage (low profit, low potential, limited upside). The company leverages its segmentation scheme to identify and market to the most attractive prospects. The company overlays its internal customer segmentation data on top of external, consumer data, to identify best prospects. It is looking for customers that are most similar to the high value, high potential sub-segment. The company uses its knowledge about current customers in the high value, high potential sub-segment to focus and direct customer acquisition marketing efforts. Direct mail offers are created based on knowing what similar, current customers have purchased.

\section{Focusing on high potential prospects}

Bank of America focuses on retaining profitable customers, building account balances and increasing account profitability. Roughly 20 per cent of Bank of America's customers generate 110 per cent of its net income. The bank uses analytical software to analyse 40 different quantitative characteristics including account balances, products owned by customers and transaction history. It calculates and predicts current per customer profitability and also identifies customers at risk of defecting. The company segments its customers based on profitability to identify the most valuable customers: entry-level plus customers are nine times more profitable than entry-level customers; premier level customers are two times as profitable as entry-level plus; and private level customers are worth four times as much as premier level customers. The company makes its segmentation operational by tagging customers based on their assigned profitability tier and the risk level of defection. This enables customer service representatives to know almost immediately how to handle each customer at the point of contact. Different offers and service levels are predetermined for each profitability tier and risk level and communicated to service representatives. For example, when a customer deposits over US $\$ 25,000$, they are flagged to receive a call from a private banker. Focusing on the most profitable customers has led to positive results for this company. The profit per customer has increased by 
nearly US $\$ 10$ (less cost of funds). The acceptance of retention offers has increased by 33 per cent. Voluntary attrition has decreased by 13 per cent and customer balances have increased by an average of 45 per cent over initial levels.

\section{Predicting future purchase patterns}

This top ten US insurance company uses predictive modelling to identify and market to customers most likely to buy specific offerings. The company aggregates current and historical customer data from all of its systems into one data-mart. It appends the internal customer data with demographic data and then creates a single, detailed profile of each customer. Using a purchase propensity model, the company determines how likely customers are to buy specific products. It identifies who buys certain products now and then overlays these customers against the entire population of current customers to determine who else may be interested in a particular product. The results are used to tailor marketing efforts for cross-selling and up-selling of offerings to current customers.

\section{Improving return on marketing efforts}

The Body Shop International, a leading UK skin-and hair-care products vendor, successfully uses segmentation analysis to improve response rate and revenue per catalogue on a new catalogue mailing. The Body Shop wanted to 1) reduce the number of catalogues mailed by 50 per cent, 2) improve the response rate of its mailings and 3) increase revenue per catalogue. The director of mail-order and new business development, Virginia Newman, said, 'We knew it was going to be a tough economic year, and we wanted to be as profitable as possible'.
The company used predictive analysis to identify the 120,000 customers most likely to buy from a catalogue mailing and most likely to have an order size greater than their historical average revenue per person. Customer data for the analysis was aggregated from several sources including: historical purchase data collected from all customer touchpoints (web, catalogue, and in-store sales), demographic data purchased from a third party and data from customer surveys. The resulting segments grouped customers according to likelihood to purchase and predicted purchase size. The results of the efforts were highly positive; overall response rate increased and revenue per catalogue increased 10-20 per cent. Following the effort, Virginia Newman, said, 'We were able to intelligently target consumers who we thought were more likely to buy and increase our revenue per catalog in a measurable way'. ${ }^{6}$

\section{Identifying new products and services}

Marriott International uses customer segmentation and brand understanding to identify opportunities for new offerings. Marriott International has a robust segmentation strategy that enables the company to gain a deep understanding of the needs and wants of both individual customers and segments of customers. Segmentation data identifies gaps between brands, eg a price point that is not offered, a customer segment that is not appropriately served, that represent opportunities for brand improvement and chances to introduce new brands. Brand improvements and expansions result when a group or segment of customers makes it known that it wants specific, new services to be provided at a current lodging brand. For example, through customer research, the company found that the price shopper segment of 


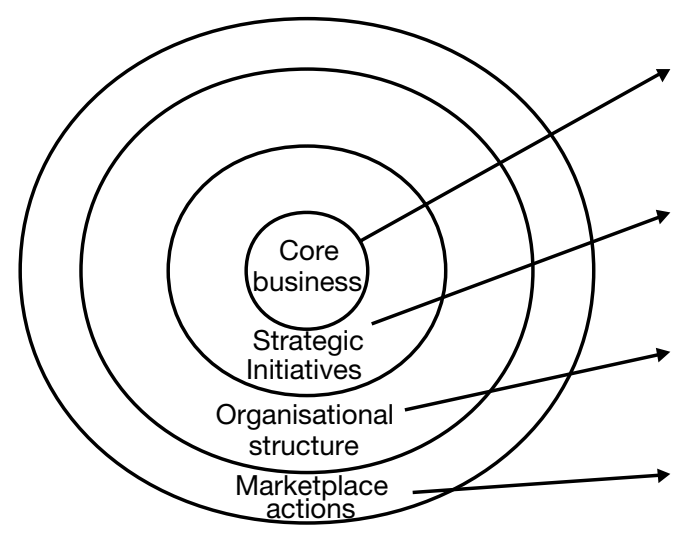

- Business strategy: How segmentation is used in development of strategy, evaluating and revising value propositions, and creating competitive advantage

- Strategic initiatives: How segmentation is used in financial planning, new product and service development, and analysis of individual initiatives

- Organisational structure: How segmentation results and customer understanding can be used to improve and modify organisational structures in order to better serve customers

- Marketplace actions: How segmentation is used to improve and focus customer acquisition and retention efforts

Figure 12 How segmentation impacts strategy and structure Courtesy of International Business Machines Corporation

customers who frequent the Fairfield Inn wanted bigger rooms with more amenities. Marriott launched a roomier version of the Fairfield Inn offering this and called the new rooms Fairfield Suites. New brands are pursued when a group or segment of customers desire a totally new set of services that are not aligned with a current brand. Through customer surveys, for example, Marriott determined that the company was not meeting the demands and expectations of elite travellers. These travellers desired superior customer service and luxurious amenities. To meet these travellers' demands, the company acquired Ritz-Carlton Hotels. ${ }^{7}$

\section{Putting it all together and making it operational}

This example is of a top financial services company that makes

segmentation operational across the entire organisation. The company uses data mining and activity-based costing to segment customers into a tiered pyramid based on profitability and assets. Within each tier, the sub-segment of customers with the highest growth potential is singled out and tagged as high potential. Many of the company's segmentation-related activities focus on retaining and migrating these high potential customers up to the next tier. Salesforces' incentive programmes are linked and aligned with the company's goal of migrating customers tagged as high potential up to the next tier of the pyramid. This company puts segmentation into action in three tactical ways. First, customer service representatives are empowered to deliver the appropriate service level based on customers' profitability. The company sets protocols for sales and service levels based on a customer's tier and sub-segment. When a teller accesses a high potential customer's record, a flag appears designating the appropriate level of service and specific offers. Secondly, sales representatives can offer 50 basis points off a loan to a customer in the high potential sub-segment, but only 35 basis points off a loan to a customer in a mid-level tier. And finally, the level and quality of phone service extended to customers is also dictated by the company's segmentation scheme. Customers in higher tiers are routed to the front of phone queues and serviced by experienced customer service representatives. The company is dedicated across the organisation to using 
its customer segmentation scheme to migrate its best customer up the pyramid to higher value.

\section{BUILDING SEGMENTATION INTO THE COMPANY}

Over three-quarters of the survey respondents actively use customer segmentation across many functional areas in their companies, from marketing and product development to business development and strategic planning. Figure 12 shows some ways this can work.

\section{Driving core business strategy}

Customer segmentation is becoming a more important part of corporate strategy development. The majority of survey respondents use segmentation either at the beginning of their strategy development process or throughout the process to help ensure the company is headed in a direction appealing to customers.

A leading health products and services retailer provides a good example of a company that sought to use segmentation to drive business strategy. The company relied on attitudinal segmentation data to rationalise the business decision to move from being a product-oriented retailer into a health services company. The company addressed several key questions with its attitudinal research:

- the extent to which current customers would be interested in a more service-oriented offering;

- whether there are attractive segments of prospective customers who might be interested in the new offering;

- the segments of customers which would be most suited to the new positioning/offerings.

Understanding the mental attitudes and needs/wants of different customer segments helped the company to structure the offering, set the prices for new services and promote offerings to the right customers. Using segmentation data enabled the company to differentiate itself from competitors. By understanding how its customers were segmented, the company was able to make informed business decisions, both strategic and tactical, that significantly increased its sales. For example, the decision was made to discontinue certain product categories and offer new product categories, resulting in sales increases. This company is at a significant competitive advantage, they know their customers better than 90 per cent of retailers in their region and they actively use this knowledge to win in the marketplace.

A leading international hospitality company also uses customer segmentation data to drive key business strategy decisions. It uses customer segmentation to refine and expand value propositions, to develop and revise customer service and brand strategies, and to prioritise strategic initiatives at both the corporate level and the individual brand level. This company has a franchise business model and uses segmentation results to gain widespread buy-in and to rally support from franchise owners. For example, segmentation data were used to reinforce (prove) the vision statement and strategy around a specific, new brand that overlapped with a current offering. Segmentation results were used to develop a unified marketing communications plan by which all franchise owners and constituencies abide. Segmentation enables the company to tailor marketing communications for each brand and customer segment and is particularly useful in training and empowering front-line employees to deliver appropriate services. 


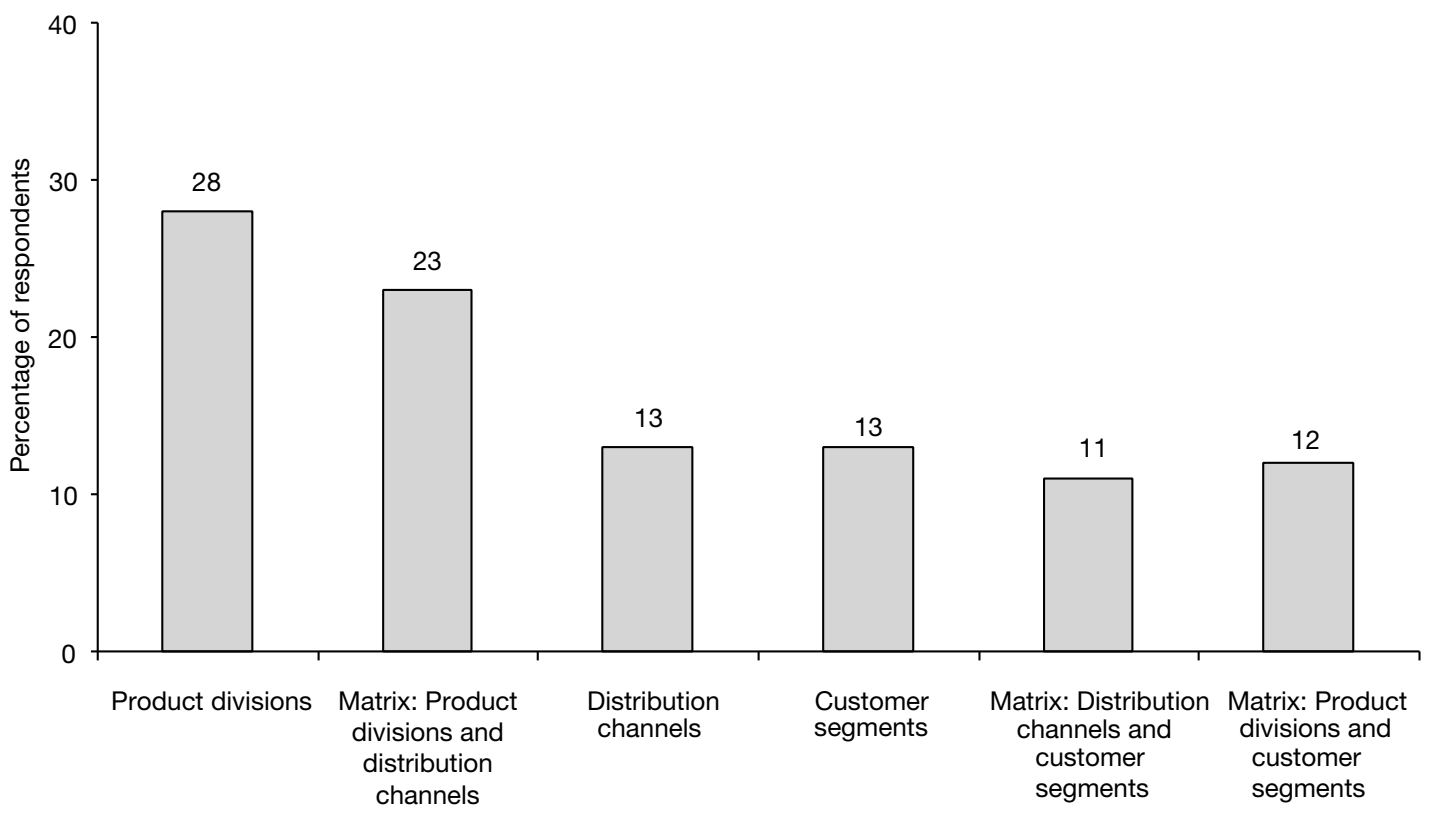

Figure 13 Organisation structure: What is your company's primary organisational structure? (IBM quantitative online survey, 122 responses)

Courtesy of International Business Machines Corporation

\section{Improving strategic initiatives}

Respondents told the authors that the results of segmentation studies are used to focus and direct many of their strategic initiatives. For example, some companies find segmentation data valuable for their product development groups.

\section{Optimising organisational structure:}

Figure 13 shows the extent to which respondents used segmentation in determining company organisation.

Sony used segmentation to create an entirely new organisational structure. In early 2002, to better understand and serve customers, Sony reorganised, internally and externally, by customer segments. It decided to reorganise by customer segments to enable the company to target products and services according to customers' life stages, preferences and needs. An in-depth segmentation study resulted in the creation of new customer segments - the segments are: affluent; CE alphas (early adopters); zoomers
(55+); SoHo (small office/home office); young professionals/D.I.N.K.S (double income no kids, 25 to 34); families (35 to 54 ); and gen Y (under 25). Based on this segmentation, the company shifted to a new segmentation-based organisational structure. This shift affected leadership positions and the company's go-to-market strategy across all divisions, including marketing, product development, retail merchandising, advertising and consumer loyalty programmes. In the past, products were owned by and marketed by product managers. In the new organisation, executives are assigned to champion and manage customer segments. Additionally, the new product development division was reorganised and given the mission of designing a new generation of products based on preferences of identified customer segments.

Sony created a new division called the consumer segment marketing division to support the reorganisation. The new division provides segmentation research and analysis for marketing 
communications across each segment and works to 'develop an intimate understanding of Sony's end consumers ... from cradle to grave'. The company is committed: 'Beginning with the new fiscal year, we will create and report a virtual $[\mathrm{P} \& \mathrm{~L}]$ that restates our [approximately] $\$ 8$ billion consumer business by consumer segments' ${ }^{8}$

\section{Making segmentation a way of life}

A leading diversified retailer uses cross-company segmentation to gain the deep customer understanding needed to drive strategic decisions. Segmentations are based on historical transaction data (from the last four years), survey data, interview data and third-party data. The company conducts segmentation using several types of customer understanding: behavioural patterns, demographic, attitudinal and financial. An executive from the company explained a key aspect of how they ensure buy-in, 'Regardless of how it's developed, segmentation must be intuitive, or people will not believe it or buy into it'. The company gains corporate buy-in in many ways. Each month, the customer advisory council, which includes the chief executive officer and direct reports, has a formal meeting. The main topic is making segmentation operational and the goal is to get buy-in of top level management. The company also holds 20 or more, three-hour, one-on-one meetings with key vendors. At these vendor meetings, executives report to vendors the results of segmentation studies and explain in detail what customers look like, why customers come to this company versus a competitor, and how customers are similar and different. Regularly, the company holds meetings with the heads of each of the lines of business to determine how to make cross-company segmentations operational at line of business level.

\section{CONCLUSIONS}

Effective customer segmentation can contribute to a company's success far beyond determining its next marketing promotion. A comprehensive, dynamic multidimensional approach will help ensure that companies know their customers and are equipped to take full advantage of what they learn about their customers to serve them better. The resulting knowledge about customers should not only be used extensively in marketing contexts, but also throughout the company, making the customer an integral part of strategy and decision making. Companies relying on segmentation only for traditional marketing efforts must, however, expand their use of segmentation. Companies should use segmentation throughout the organisation and across different functions. To take full advantage of segmentation's potential, companies should also use it to improve forecast accuracy, to direct strategy development and to determine organisational structure.

(C) IBM Corporation 2005

\section{References}

1 Levy, D. (2001) 'Segmentation: Key to efficient CRM', DM Review, September.

2 'Mr. and Mrs., meet Mr. Clean - Young couples starting out are every marketers dream', Wall Street Journal, January 2003.

3 'Slices of life - Customer segmentation', CIO Magazine, August 2000

4 'E-business in a (data) warehouse', Line56.com, October 2001; Bogatz, G. (2002) 'Product-centric to customer-centric: Why CRM is the business strategy for school-market success', MarketingWorks, Inc., November.

5 'Where the money is', Fortune, August 2001; HNC Bank of America Case Study, 2002; Exchange Applications, 2001

6 'Companies boost sales efforts with predictive analysis', Informationweek.com, February 2002

7 'Super segmenter Part I \& II', 2000 Kotler Marketing Group.

8 'New approach: Sony marketing aims at lifestyle segments', Advertising Age, March 2002. 